\title{
A Systemically Collaborative Approach to Achieving Equity in Higher Education
}

\author{
Richard J. Prystowsky
}

\begin{abstract}
Colleges and universities have long recognized the need to address inequities affecting students from underrepresented or underserved groups. Despite efforts undertaken by dedicated individuals, large-scale, national change in this area has not been realized. In this article, we address two major factors underlying this disappointing result (the structures of isolation common in our institutions of higher learning, and the inadequate addressing of our own implicit biases) and offer a model of systemic collaboration aimed at ameliorating these problems so that colleges and universities throughout the nation can achieve the equity goals that have proved so elusive for so many of them.
\end{abstract}

Keywords: equity; diversity and inclusion; implicit bias

In recent years, we have seen an increasingly urgent call to action for higher education institutions to meet the needs of underrepresented and underserved students. Though disturbing equity gaps and related disparities have persisted for decades in our institutions, the increasing numbers of such students on our campuses has made it difficult for us to avoid seeing the problems faced by these students. Inequity, long a higher education problem hidden in plain sight, in good conscience can no longer be ignored. (For excellent, trenchant explications of both the equity-related issues at stake and cogent ways of addressing these issues, see Witham et al., 2015, McNair et al., 2016, and Ramaley 2014). In order to address this urgent problem, higher education institutions need to embrace "a paradigm shift in thinking about equity, diversity, and student learning” (McNair et al., 2016). In this new paradigm, “campus educators understand and value the assets that students bring to educational experiences, as well as the importance of institutional change and continuous improvement to better meet the needs of students, whatever they may be” (McNair, 2016). In short, instead of seeing underrepresented or underserved students' underperformance or other struggles through a deficits-oriented lens, "equity-minded individuals reflect on their own and their colleagues' role in and responsibility for student success" (Bensimon, 2007). Ultimately, as McNair (2016) and McNair, et al. (2016a), suggest, this paradigm shift should help colleges and universities enact "equity-minded" policies and practices, enabling them to become "student-ready" and thereby be well-positioned to help all students experience inclusiveness, a quality education, and academic success.

\section{Operation 100\%: Committing to Equity and Inclusive Excellence, and the Problem of Implicit Bias}

The need, if not the urgency, to ameliorate the problem of persistent equity disparities in higher education is not new. However, despite the best intentions of many of our colleagues - in many cases, over the course of years - we have yet to witness industry-wide excellent results. To address this issue substantively, our institutions must enact radical, scalable, sustainable, comprehensive changes to our thinking and practices, however uncomfortable such changes 
might be for us. Without such introspection and concomitant actions, our good-faith, conscious intentions to create meaningful, lasting change could be severely undermined by our unexamined biases and initiative-crippling self-deception. Such important,courageous self-reflection must occur within an institutionally supportive, trusting environment. For if institutions do not provide such an environment in which this difficult work is to be accomplished, even highly committed employees might feel defensive or even threatened, and could very likely stop engaging in the work.

When I was Provost at Lansing Community College (LCC), we faced the problem of low student retention and completion rates, a common problem in America's community colleges. In response, we developed and implemented a bold, comprehensive, culture-changing initiative called “Operation 100\%.” I had introduced this initiative to the college after having observed persistently limited success, by faculty and others, with good-faith, yet often more or less isolated, attempts to address student success barriers. For example, dedicated faculty had been attempting to reform developmental education, an area that, nationally, is particularly prone to disparate impacts related to equity gaps. Student Affairs personnel had been working hard to assist struggling students (with tutoring and advising, for example). IT colleagues had been trying to improve instructional delivery options. However, these and other efforts were not coordinated under a college-wide, unifying, centralized, integrated, comprehensive approach to addressing student success barriers at the college. Thus their effects were limited. Operation $100 \%$ presented the vision and outlined practices for just such a unifying approach.

The goal of Operation $100 \%$ is to ensure that every student in a certificate, degree, or transferpathway will succeed in realizing her or his educational dreams. Emphasizing, and grounded in, collaboration among individuals across all areas of the college, this initiative has, among its outcomes, enabled cross-functional teams to design guided program pathways for all students and to begin designing a guided registration process that will keep students on track, and it has led to the hiring of a cadre of specially trained academic success coaches who, working with students and collaborating with college personnel, have the laser-focused task of helping students overcome non-cognitive impediments to the students' success in courses and programs (Prystowsky et al., 2015). Indeed, Operation 100\% has galvanized the college and brought together colleagues from Academic Affairs, Student Affairs, IT, Financial Aid, and other areas to work towards the common goal of helping all students succeed at LCC.

As I led this culture-changing initiative, I found that colleagues from across the college were eager to join the effort. What became clear, as well, was the extent to which higher education is systemically structured to facilitate employees' separation (or even isolation) from rather than their collaboration with other employees. For example, normally, we hire faculty to teach courses or sections of courses, to be part of a department, division, and school, and so on. We do not normally hire faculty to be employees of the institution, charged with cross-functional teamwork responsibilities. The same holds true for other employee appointments in other areas of the college. Clearly, institutions need to divide workloads and assign responsibility and accountability accordingly. Commonly, though, we find it difficult to break out of our silos. In leading Operation 100\%, I discovered that, because this initiative is grounded in the concepts and practices of cross-functionality and collaboration, it provides employees with a systematically solid way to work together towards the common goal of helping all students succeed. As I have 
noted, colleagues from across the college were eager to embrace this opportunity. The problem, I discovered, was not that they had been unwilling to engage in this kind of comprehensive, collaborative effort or that, in more limited ways, they had not already engaged in collaborative work; rather, they had not yet been given the chance to do so by working towards achieving a focused student success goal in a college-wide, comprehensively unifying way.

And yet, despite our enthusiasm, we also found ourselves faced with the discomforting data indicating that students from underrepresented groups were not performing as well as other students in, for example, key gateway courses or developmental education courses. Looking at these outcomes through an equity-minded lens, we realized that we had to be honest with ourselves concerning the extent to which our own implicit biases might be undermining our efforts to be a student-ready college for all of our students.

Fortunately, having become involved with the Association of American Colleges and Universities' (AACU) “Committing to Equity and Inclusive Excellence” project, we were well positioned to carry out this examination. (For a sampling of AACU publications addressing the equity imperative, see AACU, 2015a; AACU 2015b, and Witham et al., 2015.)

For example, in discussing how to close equity gaps for African American and Latina/Latino students - the focus of our AACU work-we reminded ourselves that, in light of the United States' history of racism, sexism, heterosexism, and similar societal ills, no one growing up in our country could likely escape the messages and influences of these problems. Were we not to confront this problem in ourselves, then, we could jeopardize our equity-minded work insofar as we might limit our ability to see the extent to which our own attitudes and behavior could be contributing to the persistence of equity gaps for underrepresented students. Key to doing this work well was our coming to terms with our own implicit biases, an endeavor that required us to understand that, compared to explicit biases, implicit biases are or can be especially problematic precisely because they are unconscious, not easily recognized, and thus difficult to address. As noted by researchers Mahzarin Banaji and Anthony Greenwald, even good people have hidden biases (Banaji and Greenwald 2013).

We thus decided that we needed to take a deep dive into addressing this problem, lest we undermine our work with Operation $100 \%$ by failing to close the equity gaps in student success that we were seeing. A number of us who were already familiar with scholarship on the effects of implicit bias thus felt that a good starting point would be for the college to engage in implicit bias awareness training. (For detailed information concerning LCC's implicit bias awareness training in particular and the college's diversity-related work in general, see Prystowsky, et al., 2017a; Prystowsky \& Heutsche, 2017b. For information on how other higher education institutions might use knowledge of implicit bias to effect meaningful, diversity-related change, see Davies, 2016.) To maximize the benefits of this self-reflective work and minimize persons' discomfort with it, we decided to hire an outside consultant who could lead train-the-trainer sessions for us. We also agreed to create and sustain an atmosphere of "no blame, no shame.” In such an atmosphere, we would work from intentionality and good faith. Furthermore, we would support each other, even when — and sometimes especially when-our efforts were not producing desired results. As alluded to above regarding the need to create and sustain a trusting, supportive environment in which to carry out this work, we worried that, if persons confronting 
their own possible implicit biases felt that they were being blamed or shamed, they could become defensive and stop engaging in the work.

Given this understanding, from general meetings open to all (such as semester-opening events) to smaller meetings with specific groups (such as search committees), from time to time we reminded each other that none of us is born with implicit biases, that both victims and nonvictims have learned and internalized such biases to greater or lesser degrees and in various ways, and that, without blaming or shaming, we needed to carry out our equity-related work in a supportive context. From my own observations in numerous meetings, colleagues responded well to this approach, engaging in the self-reflective work openly and honestly.

\section{Implicit Bias Training}

We engaged the services of a consultant from "Project Implicit," a research organization that contributes to the public's awareness of hidden biases (see https://implicit.harvard.edu/implicit/). We involved our consultant twice. On his first visit, he worked with the "Committing to Equity and Inclusive Excellence” steering committee; on the second visit, he worked with advisors, support staff, and others from the college. For each training, I asked participants to prepare for the meetings by familiarizing themselves with Project Implicit and by taking one or more of the Implicit Association Tests (IATs) offered on its website. Knowing that results from these tests might be disturbing (again, even "good persons" have implicit biases), I asked that participants take the tests privately. In his work with us, the consultant had us take a few of the tests as a group so that no one would feel personally implicated and vulnerable.

Perhaps not surprisingly, when the steering committee took the IAT on race, as a group we associated "good" with Whites more than we did with Blacks and "bad" with Blacks more than we did with Whites. This result reinforced for us that even the steering committee for the college's equity project - that is, the choir of the choir — could not escape the nefarious influences of racism in our culture. Again not surprisingly, when the larger group of participants took the IAT on race, the outcome was similar. The conclusion for us was obvious: None of us is immune from having implicit biases, which we needed to confront if we were to advance our equity-oriented work.

\section{Faculty Involvement}

To be as inclusive as possible in our work, we engaged in implicit bias awareness training with faculty, support staff, and others. I offer two examples here to illustrate the nature and outcomes of this work, the first of which involves faculty, and the second of which involves search committees.

In LCC's program review process, faculty analyzed data related to race and gender disparities in program enrollments, degrees awarded, and the like. In the post-review discussions, we then focused on examining the extent to which implicit biases might play a role in these disparities. The college is currently following up on these discussions with additional implicit bias awareness training for program faculty and staff and with annual improvement action plans that incorporate efforts to improve diversity-related outcomes-for example, efforts to strengthen the 
recruiting of students, advisory committee members, and program faculty from underrepresented groups. At this point, the work is in initial phases of development; anecdotal evidence suggests promising results in addressing targeted concerns, though.

\section{Impact of Implicit Bias Training on the Curriculum and Campus Policies and Practices Curriculum:}

Faculty have been actively involved in other equity-minded and diversity-related efforts as well. For instance, during start-of-semester professional activity days, faculty led seminars on implicit bias barriers to student success and held a college-wide meeting on ways that LCC might continue to strengthen its work in committing to equity and inclusive excellence. Seminar discussions involved ways to revise curricula, teaching methods, and assignments so that classes would effect inclusiveness along with high quality education.

In a college-wide meeting, participants discussed ways in which the college as a whole could remove barriers to student success. For example, by making it easier for students to find academic and non-academic support, by revising payment policies that address the needs of firstgeneration, low-income students, and so on. Still in the beginning stages, this work bodes well for student success at the college. It also has yielded professional development opportunities for faculty, who have expressed that they feel both energized by and supported in continuing to do the work.

\section{Gateway Courses}

The effects of our work are perhaps nowhere more apparent than in the exciting work being undertaken by faculty participating in the college's newly developed Faculty Institutes, an outgrowth of the AACU-related equity work that has benefited from LCC's ongoing implicit bias awareness training. Led by the college's Chief Diversity Officer (CDO), these Institutes focus on helping faculty understand how to maximize their efforts to engage at-risk students. Because LCC's retention data indicate that students from underrepresented groups are particularly at risk in key gateway courses (which LCC defines as courses having both high enrollments and high DFWI rates) the college initiated the Institutes with faculty teaching these courses (Accounting and History at first, with additional courses to follow). The CDO helps faculty learn how to engage in authentic communication with students, create alternative lessons that are relevant and meaningful to students, and the like. Student evaluations indicate positive

satisfaction, faculty feedback indicates enthusiasm and engagement, and course completion data indicate positive increases. LCC will continue to assess this work as it scales up faculty involvement in the Institutes. The results thus far bode well.

Search Committees

To help ensure that LCC apply diversity awareness to its hiring processes, I led implicit-bias awareness training as part of search committee orientations. Search processes at colleges and universities often result in "the appointment[s] of persons who look, think, or otherwise seem like the faculty and staff already employed by our institutions-despite the diversity training received by search committee members, and despite a professed institutional commitment to 
diversifying the faculty and staff." Indeed, the "message often sent by the practical results of our thinking and behavior can be summed up as follows: 'It's okay to be different, as long as you're not'” (Prystowsky et al., 2017a and Prystowsky, 2008). As is the case with challenging what Ronald Takaki refers to as "the master narrative" underlying dominant culture thinking and practices, challenging the general and often unexamined mindset that "it's okay to be different, as long as you're not” has proved to be quite difficult (Takaki, 2008).

To help ameliorate this problem at LCC, I oriented search committees on implicit bias awareness, helping them both to understand its root causes and to see how they can keep biases from affecting the search process. Some specific examples of this work follow. After reinforcing the notion that none of us is immune from having implicit biases, I asked that the search committee members see themselves as a confidential, trusting support network for each other as they engaged in their work to hire personnel. Among the pieces of information and advice that I discussed with search committee members is that which reflects another key takeaway from the training that our consultant did with us at the college: to wit, that implicit biases are more likely to emerge when decision-making criteria are not clear. Thus, I advised search committee members to be sure that they were working with clearly stated criteria. However, I also advised that they not be too restrictive in criteria development, lest they unintentionally undermine their efforts to be open-minded and inclusive during the search. For example, I recommended that, unless an accrediting body requires specific numbers of years of experience, search committees require that candidates have "experience" rather than a specific number of years of experience. This seemingly slight change can have major consequences in developing an applicant pool that widens the net of inclusivity for candidates from underrepresented groups.

Although this work, too, is new to the college, preliminary results are again promising. For example, search committees have revised interview questions accordingly and personnel are investigating ways to make initial applicant screening "blind.” By talking about cultural biases that favor individualism over the community, I helped search committees avoid constructing interview questions that could unintentionally either advantage or disadvantage particular groups of persons. In this regard, I assisted search committees with developing relational questions, which candidates from any culture ought to be able to answer and which allow search committee members to evaluate how a candidate might work with others to effect a common good (for a department, the college, or the community, for example). However, I also cautioned that search committees be careful about looking for "fit" in a candidate. Not uncommonly, a search for "fit" leads to the hiring of persons just like the persons already employed by the college, even though other, less conspicuously "fitting” candidates might help the college grow in positive ways not yet recognized.

One particular interview danger related to "fit" manifests itself in the still commonly asked question "Why are you the best candidate for the position?" A candidate from a culture that emphasizes community and not individuality might be disadvantaged by this interview question, whereas a candidate whose culture promotes, for instance, rugged individualism might be advantaged by it. In any case, if we are honest about this all-too-common interview question, we would have to admit that no candidate could answer the question accurately who has not reviewed all of the applications first and somehow discovered that, objectively, she or he is the 
best candidate. Suffice it to say that this question is at least culturally biased and at most disingenuous. I strongly recommend that search committees never use it or any variant of it.

There are other good equity-related recommendations for search committees to follow: for example, their asking open-ended questions and listening with an open mind, not predetermining the "right" answer to the question; and their having the candidate sit among the search committee members rather than at the head of the table (this arrangement helps to emphasize the importance of relationships, and it de-emphasizes a valorization of the self). Different search committees at different institutions will need to develop equity-related questions and search practices appropriate to their own institutions' needs. If they are guided by equity-mindedness, though, and if they are willing to address their own hidden biases, all search committees ought to be able to engage more consistently than before in fair-minded, equity-oriented hiring practices.

\section{Conclusion}

Lansing Community College's equity-minded, self-reflective efforts can be summed up by the vision statement for Operation $100 \%$, which derives from the college's work to strengthen equity, diversity, and inclusion at the college: " $100 \%$ Success Through $100 \%$ Inclusion.” To be sure, this kind of work is sometimes challenging. However, given the potential for higher education to change lives and communities in dramatically scalable fashion, especially with respect to individuals and communities traditionally underrepresented in or underserved by our institutions, in good conscience we have no choice but to engage in these efforts. Indeed, this endeavor is a matter of conscience, and our work in this regard is the work of justice. Our students have entrusted us to help them achieve their higher education dreams. We have a moral obligation to help them - all of them —including, and perhaps especially, our students who have not been well served either by our society or by institutions of higher learning.

To be sure, meaningful, lasting change takes time. But we cannot wait. We need to act now. On our campuses are entire groups of traditionally underrepresented or underserved students, faculty, and staff, whose individual and collective strengths and attributes are waiting to be fully realized. These fellow citizens can do so much to help enrich us all. In the final analysis, we need to ask, at whose risk can we truly afford to wait any longer — and at what cost to us all? 


\section{References}

AACU. (2015a). Committing to equity and inclusive excellence: A campus guide for self-study and planning. Retrieved from https://www.aacu.org/publications/committing-to-equity

AACU. (2015b). Step up \& lead for equity: What higher education can do to reverse our deepening divides. Retrieved from https://aacu.org/publications/step-up-and-lead

Banaki, Mahzarin R \& Anthony G. Greenwold. (2013). Blindspot: Hidden Biases in Good People. New York: Delacorte Press.

Bensimon, E.M. (2007, Summer). The underestimated significance of practitioner knowledge in the scholarship on student success. The Review of Higher Education, 30(4), 441-469. https://doi.org/10.1353/rhe.2007.0032

Davies, S.L. (2016, Fall). Driving campus diversity one decision at a time. Liberal Education, 102(4), 46-51. Retrieved from https:/www.aacu.org/liberaleducation/2016/fall/davies

McNair, T.B. (2016). The time is now: Committing to equity and inclusive excellence. Diversity and Democracy, 19(1), 4-7. Retrieved from https:/www.aacu.org/diversitydemocracy/2016/winter/mcnair

McNair, T.B., Albertine, S., Cooper, M.A., McDonald, N., \& Thomas Major Jr., (2016a). Becoming a Student-Ready College: A New Culture of Leadership For Student Success. San Francisco: Jossey-Bass

Prystowsky, Richard J. (2008). It's okay to be different, as long as you're not. Encounter 21(1), 37-39. Retrieved from http://www.great-ideas.org/enc.htm

Prystowsky, R.J., Koch, A.K., \& Baldwin, C.A. (2015). Operation 100\%, or, completion by redesign. Peer Review, 17(4), 19-22. Retrieved from

https://www.aacu.org/peerreview/2015/fall/prystowsky

Prystowsy, R.J, Herrera, J., Crowley, C., Lowery-Hunt, R., \& Fannon, S. (2017a). Grabbing third rails: Courageous responses to equity gaps. Liberal Education, 103(2), 44-49. Retrieved from https://www.aacu.org/liberaleducation/2017/spring/prystowsky

Prystowsky, R.J. \& Heutsche, A.M. (2017b). Facing ourselves, engaging our students: Equityminded practices at work. Peer Review, 19(2), 25. Retrieved from https://www.aacu.org/peerreview/2017/Spring/Prystowsky

Ramaley, J.A. (2014). Educating for a Changing World: The Importance of an Equity Mindset,” Metropolitan Universities Journal, 25(3): 5-15. Retrieved from

https://journals.iupui.edu/index.php/muj 
Takaki, R. (2008). A Different Mirror: A History of Multicultural America. New York: Bay Back Books.

Witham, K., Malcom-Piqueux, L.E., Dowd, A.C., \& Bensimon, E.M. (2015). America's Unmet Promise: The Imperative for Equity in Higher Education. Washington, DC: Association of American Colleges and Universities. 


\section{Author Information}

For more than fifteen years, Richard J. Prystowsky has held administrative leadership positions at various community colleges, most recently at Lansing Community College, where he was Provost. He is currently the Vice President of Academic Affairs and Student Services at Marion Technical College, in Ohio. Previously, at Irvine Valley College, he held a dual appointment as a professor of English and Humanities, teaching courses in writing, literature, and humanities, and specializing in Holocaust Studies. The author of a college-level writing text (Careful Reading, Thoughtful Writing), he has also published articles, given talks, or led sessions on a variety of topics, including education, diversity and inclusion, writing, literature and psychoanalysis, nonviolence, Holocaust Studies, and peace studies. For the entirety of his career, he has been a strong advocate for higher education's enacting substantial policies and practices that advance the work of equity, diversity, and inclusion. He sees this work as integral to higher education's commitment to helping create a well-educated, civically engaged, humanitarian-oriented citizenry.

Richard J. Prystowsky, Ph.D.

Vice President of Academic Affairs and Student Services

Marion Technical College

1467 Mt. Vernon Ave.

Marion, OH 43302

Email: prystowskyr@mtc.edu

Telephone: 740-386-4150 